\title{
Regional Distribution of Cardiologists and Prescription Patterns of Sodium-Glucose Transporter-2 Inhibitors in Japan
}

\author{
Daisuke Inoue, ${ }^{1} \mathrm{MD}$, Hiroshi Nishi, ${ }^{2} \mathrm{MD}$, Reiko Inoue, ${ }^{2} \mathrm{MD}$ and Masaomi Nangaku, ${ }^{2} \mathrm{MD}$
}

\begin{abstract}
Summary
The clinical evidence is accumulating since 2015 that anti-diabetic sodium-glucose cotransporter 2 (SGLT 2) inhibitors have the beneficial effect of cardiovascular and, recently, renal protection. Although it is not well analyzed how the transfer of this new evidence into daily practice has expedited, we hypothesize that the recent usage of the drugs is positively associated with several certified cardiologists in each region.

The 2016 annual and 2016-2017 increased number of SGLT2 inhibitor tablets, based on the National Database of Health Insurance Claims and Specific Health Checkups of Japan, were divided by the estimated number of patients with type 2 diabetes mellitus for each of the 47 prefectures. Then, regression analyses were performed to investigate the potential association of the number of certified cardiologists with the drug prescription.

The 2016 prescription of ipragliflozin, dapagliflozin, luseogliflozin, canagliflozin, and empagliflozin was 2.7- to 4.4-fold different between prefectures. The 2016-2017 increased prescription volume also varied among prefectures by as large as 7.3-fold for ipragliflozin. Regression analysis revealed that the annual and increased prescription volume of all the SGLT2 inhibitors except luseogliflozin were higher in regions with more certified cardiologists $(P<0.05)$, even after adjusting for regional parameters.

In conclusion, the regional number of certified cardiologists was positively associated with a 2016 annual of and 2016-2017 increase in SGLT2 inhibitor prescription amount, implying an early adopter role of clinical experts in healthcare delivery.
\end{abstract}

(Int Heart J 2021; 62: 592-600)

Key words: Nationwide database, Regional variation, Clinical experts, Diabetes mellitus, Cardiovascular protection

$\mathrm{S}$ odium-glucose cotransporter 2 (SGLT2) inhibitors are a class of glucose-lowering agents that have a high profile because, in recent large-scale clinical trials, they have demonstrated unprecedented cardiovascular benefits for patients with type 2 diabetes mellitus (T2 DM). ${ }^{1-3)}$ In 2015, the Empagliflozin Cardiovascular Outcome Event Trial in Type 2 Diabetes Mellitus PatientsRemoving Excess Glucose (EMPA-REG OUTCOME) study was the first to show the beneficial effect of empagliflozin on cardiovascular mortality and morbidity. ${ }^{1}$ Furthermore, the Canagliflozin Cardiovascular Assessment Study (CANVAS) in 20172) and the Dapagliflozin Effect on Cardiovascular Events-Thrombolysis in Myocardial Infarction 58 (DECLARE-TIMI 58) trial in 2019) reported cardiovascular protection by canagliflozin and dapagliflozin, respectively. The subsequent meta-analysis revealed that SGLT2 inhibitors reduced cardiovascular disease and death in patients with T2DM. ${ }^{4)}$ Recently, the protective effect of SGLT2 inhibitors in non-diabetic patients with heart failure and a reduced ejection fraction was demonstrated in Dapagliflozin on the Incidence of Worsening
Heart Failure or Cardiovascular Death in Patients with Chronic Heart Failure (DAPA-HF) and the Empagliflozin Outcome Trial in Patients with Chronic Heart Failure and a Reduced Ejection Fraction (EMPEROR-Reduced). ${ }^{5,6)}$ However, results with the newer SGLT2 inhibitor ertugliflozin were less dramatic.") Although high expectations among clinicians are growing for the cardiovascular benefits from SGLT2 inhibitors in diabetic and non-diabetic patients, clinicians should be carefully aware of the latest evidence on SGLT2 inhibitors.

At least currently, SGLT2 inhibitors should suitably reach patients with T2DM as per the official recommendations, including the American Diabetes Association guide$\operatorname{lin}^{8,9)}$ and the Japan Diabetes Society guideline. ${ }^{10)}$ Those recommendations will be updated constantly based on the latest evidence of the moment. However, clinical evidence and official guidelines are not enough for medications to benefit patients in practice. Clinical practitioners should put evidence into their daily practice via appropriate drug prescription, contributing to further narrowing the evidence-practice gap. ${ }^{11}$ The preliminary step toward re-

From the ${ }^{1}$ Division of Nephrology, Department of Medicine, Mitsui Memorial Hospital, Tokyo, Japan and ${ }^{2}$ Division of Nephrology and Endocrinology, Graduate School of Medicine, The University of Tokyo, Tokyo, Japan.

Address for correspondence: Hiroshi Nishi, MD, Division of Nephrology and Endocrinology, Graduate School of Medicine, The University of Tokyo, 7-3-1 Hongo, Bunkyo-ku, Tokyo 113-8655, Japan. E-mail: hrnishi-tky@umin.ac.jp

Received for publication October 28, 2020. Revised and accepted December 9, 2020.

doi: $10.1536 /$ ihj.20-716

All rights reserved by the International Heart Journal Association. 
solving the gap is to grasp the current distribution pattern of SGLT2 inhibitors. However, few studies have attempted to focus on the sociodemographic factors associated with the prescription of SGLT2 inhibitors. ${ }^{12-14)}$ In the United Kingdom (UK), ethnicity was an essential determinant of prescription inequality for SGLT2 inhibitors, while sex and socioeconomic status did not make a contribution toward inequality. ${ }^{12)}$ In a retrospective cohort study using the Royal College of General Practitioners Research and Surveillance Centre (RCCGP RSC) database, individuals of Asian or African ethnicity were less likely than those of White ethnicity to be prescribed SGLT2 inhibitors. ${ }^{12}$ Moreover, a nationwide cohort study in the United States (US) showed that African Americans were less likely to be on SGLT2 inhibitors than their non-Black counterparts. ${ }^{13)}$

These analyses noted differences in the prescription of SGLT2 inhibitors based on patients' ethnicity; however, studies on factors other than ethnicity have been limited. The less ethnically heterogeneous population of Japan enabled us to study factors associated with prescriptive disparities of SGLT2 inhibitors, other than ethnicity. Therefore, the present study aims to examine regional prescription patterns of SGLT2 inhibitors in the country and to identify factors contributing to these patterns, utilizing the nationwide databases.

\section{Methods}

The National Database of Health Insurance Claims and Specific Health Checkups of Japan: Since 2008, the Japanese Ministry of Health, Labor and Welfare has developed a database, known as the National Database of Health Insurance Claims and Specific Health Checkups of Japan, or NDB, which is a comprehensive database of all health insurance claims covered by the Japanese National Health Insurance system. We obtained claim data related to SGLT2 inhibitor prescription in each of the 47 prefectures in Japan from the third and fourth versions of NDB Open Data Japan. The third and fourth versions had the health insurance claim information for 2016 (April 2016 to March 2017) and 2017 (April 2017 to March 2018). In Japan, oral medications prescribed by a hospital (clinic) outpatient services are dispensed either in the hospital (clinic) or by out-of-hospital pharmacies. The NDB provided separate prescription claims outputs for these different dispensing agencies. The analysis included both inhospital and out-of-hospital outpatient prescriptions to the exclusion of inpatient prescriptions.

Of the SGLT2 inhibitors currently marketed in Japan, we selected ipragliflozin, dapagliflozin, luseogliflozin, canagliflozin, and empagliflozin for the analysis. We excluded tofogliflozin because we did not have access to the accurate data regarding its in-hospital outpatient prescription claims from the NDB Open Data. Ipragliflozin first became available in Japan in April 2014; dapagliflozin and luseogliflozin in May 2014; canagliflozin in September 2014; and empagliflozin in February 2015.

Patient Survey 2017: The Ministry of Health, Labor, and Welfare conducts Patient Survey every three years. We obtained the number of patients with $\mathrm{T} 2 \mathrm{DM}$, the proportion of male patients, and those aged $>65$ years of the total number of patients with T2DM in each prefecture from the 2017 version of this survey. (https://www.mhlw.go.jp/ toukei/list/10-20.html (in Japanese) [accessed January 5, 2020]).

Medical institution variables and economic and welfare conditions: We acquired medical institution variables and economic and welfare conditions in the fiscal year 2016 by prefecture from the prefecture-specific primary data provided by the Statistical Bureau, Ministry of International Affairs and Communications (https://www.e-stat.go. $\mathrm{jp} /$ regional-statistics/ssdsview/prefectures (in Japanese) [accessed January 5, 2020]). Due to data unavailability, population density and prefectural income were acquired from the identical database in 2017 and 2015.

Each Registry of Board Certified Diabetologists and Cardiologists: The numbers of certified diabetologists and cardiologists were based on data obtained from the registry of Board Certified Diabetologists of the Japan Diabetes Society, on October 4 2019, provided by the Japan Diabetes Society (http://www.jds.or.jp/modules/senmo ni/ (in Japanese) [accessed January 5, 2020]) and Board Certified Cardiologists of the Japanese Circulation Society, on September 5 2019, provided by the Japanese Circulation Society (http://www.j-circ.or.jp/information/senmo ni/kensaku/senmoni_kensaku.htm (in Japanese) [accessed January 5, 2020]), respectively. We utilized the data in 2019 because data on the numbers of certified specialists in 2016 and 2017 were not available.

Data analysis: We acquired the total quantity of SGLT2 inhibitors prescribed in Japan in 2016 and 2017; we calculated the annual volume in 2016 and the increased prescription volume of SGLT2 inhibitors from 2016 to 2017 that were divided by the total number of patients with $\mathrm{T} 2$ DM for each region and prefecture. We first performed univariate regression analyses to evaluate the association of socio-medical factors with the annual and the increased prescription amount. Then, multiple regression analysis used several models to examine the relationship between the number of certified cardiologists (per patient with $\mathrm{T} 2$ DM) and the prescription pattern. We selected up to six explanatory variables in the ascending order of their pvalues, given the limited sample size. Then, we created the following multivariate models for the analysis of the annual prescription amount: Model 1 was adjusted for sex (the proportion of males in population with T2DM) and age (the proportion of those aged $>65$ years in population with T2DM). Model 2 was adjusted for covariates in Model 1 plus prefectural income (per person) and the number of pharmacies (per 100,000 persons); Model 3 was adjusted for covariates in Model 2 plus the number of certificated diabetologists (per patient with T2DM). We also created the following multivariate models for the analysis of the increased prescription amount: Model 1 was adjusted for sex and age; Model 2 was adjusted for covariates in Model 1 plus the number of pharmacies (per 100,000 persons); Model 3 was adjusted for covariates in Model 2 plus the number of certificated diabetologists (per patient with T2DM). $P$-values of $<0.05$ were considered statistically significant. All statistical analyses were performed using the statistical package R, version 3.6.1. 
Ethical committee approval: The study was approved by the Research Ethics Committee of the University of Tokyo Graduate School of Medicine (\#11621).

\section{Results}

Prescriptions of SGLT2 inhibitors: In 2016 and 2017, the annual total amounts of tablets claimed for each SGLT 2 inhibitor were as follows: $50 \mathrm{mg}$ ipragliflozin, $44,034,320$ and $54,637,077 ; 5 \mathrm{mg}$ dapagliflozin, $34,475,647$ and 52,006,582; $2.5 \mathrm{mg}$ luseogliflozin, $17,926,649$ and $27,296,689 ; 100 \mathrm{mg}$ canagliflozin, 21,889,434 and 35,974,014; and $10 \mathrm{mg}$ empagliflozin, $18,970,564$ and 44,269,342 (Figure 1). The annual volume of tablets claimed for each SGLT2 inhibitor from 2016 to 2017 increased by 10,602,757 (24.1\%) for ipragliflozin, $17,530,935(50.9 \%)$ for dapagliflozin, 9,370,040 (52.3\%) for luseogliflozin, $14,084,580(64.3 \%)$ for canagliflozin, and $25,298,778(133.4 \%)$ for empagliflozin.

Regional variations in the prescription pattern of SGLT2 inhibitors: The prescription pattern of SGLT2 inhibitors for each region (Hokkaido, Tohoku, Kanto, Chubu, Kinki, Chugoku, Shikoku, and Kyushu) is demon-

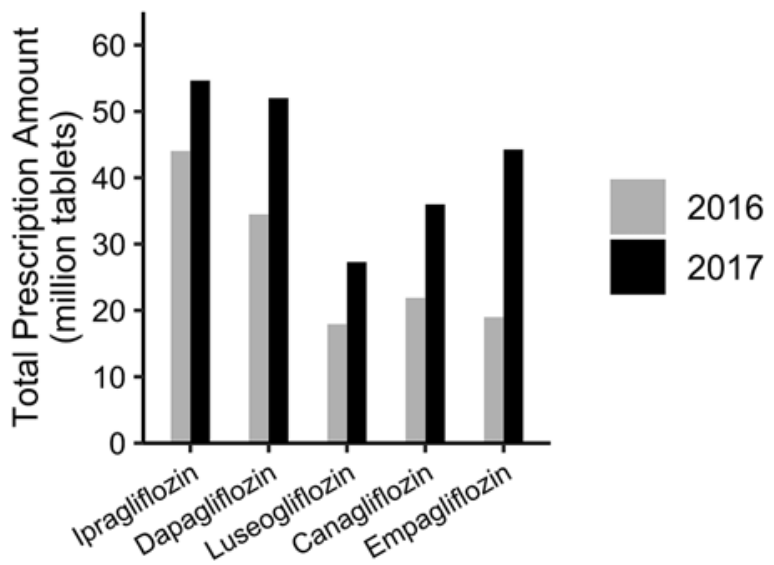

Figure 1. The total amount of SGLT2 inhibitors prescribed annually in Japan in the fiscal years 2016 (gray bars) and 2017 (black bars). SGLT2 inhibitors indicates sodium-glucose transporter-2 inhibitors. strated in Table I. In Kanto and Shikoku Regions, the annual prescription volume in 2016 and the increased prescription volume from 2016 to 2017 per patient with T2 DM were higher across all the agents of SGLT2 inhibitors than the national average. Meanwhile, compared to the national average, those numbers are lower in Kyusyu Region.

We then proceeded to analyze at a prefecture-level. The annual prescription amount of SGLT2 inhibitors divided by the number of patients with T2DM for 47 prefectures in 2016 is demonstrated in ascending order in Figure 2A. Variations among prefectures were as large as 3.6-fold for ipragliflozin (maximum Chiba, minimum Kagoshima), 2.7-fold for dapagliflozin (maximum Nara, minimum Saga), 3.9-fold for luseogliflozin (maximum Nara, minimum Shimane), 3.9-fold for canagliflozin (maximum Chiba, minimum Nagasaki), and 4.4-fold for empagliflozin (maximum Nara, minimum Shimane).

The increased prescription amount of SGLT2 inhibitors divided by the number of patients with T2DM for 47 prefectures, from 2016 to 2017, is shown in ascending order in Figure 2B. Variations among prefectures were as large as 7.3-fold for ipragliflozin (maximum Miyazaki, minimum Okinawa), 4.2-fold for dapagliflozin (maximum Chiba, minimum Saga), 3.4-fold for luseogliflozin (maximum Kochi, minimum Shimane), 3.4-fold for canagliflozin (maximum Ishikawa, minimum Nagasaki), and 3.4fold for empagliflozin (maximum Nara, minimum Nagasaki).

Association of medico-social factors with the prescription patterns of SLGT2 inhibitors: The correlation coefficients between explanatory variables and the annual prescription volume of SGLT2 inhibitors per patient with T2 DM are shown in Table II. All the SGLT2 inhibitors demonstrated a positive correlation with the number of certified cardiologists per patient with T2DM. Only ipragliflozin and dapagliflozin showed a positive correlation with the number of certified diabetologists per patient with $\mathrm{T} 2$ DM. The number of pharmacies (per 100,000 persons) negatively correlated with the annual prescription of SGLT2 inhibitors except for empagliflozin. No other consistent relationships were observed.

The correlation coefficients between explanatory vari-

Table I. The Annual Prescriptions and the Increase in Prescriptions of SGLT2 Inhibitors per Patient with T2DM in Each Region

\begin{tabular}{|c|c|c|c|c|c|c|c|c|c|c|}
\hline \multirow[b]{2}{*}{ Region } & \multicolumn{5}{|c|}{$\begin{array}{l}\text { The annual prescription amount in } 2016 \\
\text { (tablets/patient with T2DM) }\end{array}$} & \multicolumn{5}{|c|}{$\begin{array}{l}\text { The increased prescription amount from } 2016 \text { to } 2017 \\
\text { (tablets/patient with T2DM) }\end{array}$} \\
\hline & $\begin{array}{l}\text { Ipragli- } \\
\text { flozin }\end{array}$ & $\begin{array}{l}\text { Dapagli- } \\
\text { flozin }\end{array}$ & $\begin{array}{l}\text { Luseogli- } \\
\text { flozin }\end{array}$ & $\begin{array}{l}\text { Canagli- } \\
\text { flozin }\end{array}$ & $\begin{array}{l}\text { Empagli- } \\
\text { flozin }\end{array}$ & $\begin{array}{l}\text { Ipragli- } \\
\text { flozin }\end{array}$ & $\begin{array}{l}\text { Dapagli- } \\
\text { flozin }\end{array}$ & $\begin{array}{l}\text { Luseogli- } \\
\text { flozin }\end{array}$ & $\begin{array}{l}\text { Canagli- } \\
\text { flozin }\end{array}$ & $\begin{array}{l}\text { Empagli- } \\
\text { flozin }\end{array}$ \\
\hline Hokkaido & 18.4 & 15.0 & 7.3 & 9.3 & 7.2 & 4.4 & 7.5 & 3.3 & 6.1 & 10.2 \\
\hline Tohoku & 20.1 & 14.0 & 8.4 & 9.1 & 8.6 & 5.7 & 6.9 & 4.0 & 7.1 & 10.9 \\
\hline Kanto & 21.1 & 15.5 & 7.8 & 11.3 & 9.8 & 5.0 & 8.1 & 4.1 & 6.2 & 12.3 \\
\hline Chubu & 19.6 & 14.2 & 8.4 & 8.9 & 7.6 & 4.4 & 7.2 & 4.2 & 6.0 & 10.9 \\
\hline Kinki & 19.7 & 16.9 & 8.6 & 10.0 & 8.0 & 4.5 & 8.4 & 4.5 & 6.3 & 11.3 \\
\hline Chugoku & 19.8 & 15.9 & 7.6 & 8.3 & 7.4 & 5.5 & 7.5 & 4.8 & 5.8 & 10.3 \\
\hline Shikoku & 20.2 & 16.3 & 8.7 & 10.0 & 10.2 & 5.6 & 6.7 & 4.9 & 7.2 & 12.7 \\
\hline Kyusyu & 11.9 & 11.7 & 5.4 & 6.1 & 5.7 & 2.8 & 6.3 & 2.9 & 4.9 & 7.7 \\
\hline $\begin{array}{l}\text { National } \\
\text { average }\end{array}$ & 18.9 & 14.8 & 7.7 & 9.4 & 8.1 & 4.6 & 7.5 & 4.0 & 6.0 & 10.9 \\
\hline
\end{tabular}

SGLT2 inhibitors indicate sodium-glucose transporter-2 inhibitors and T2DM, type 2 diabetes mellitus. 

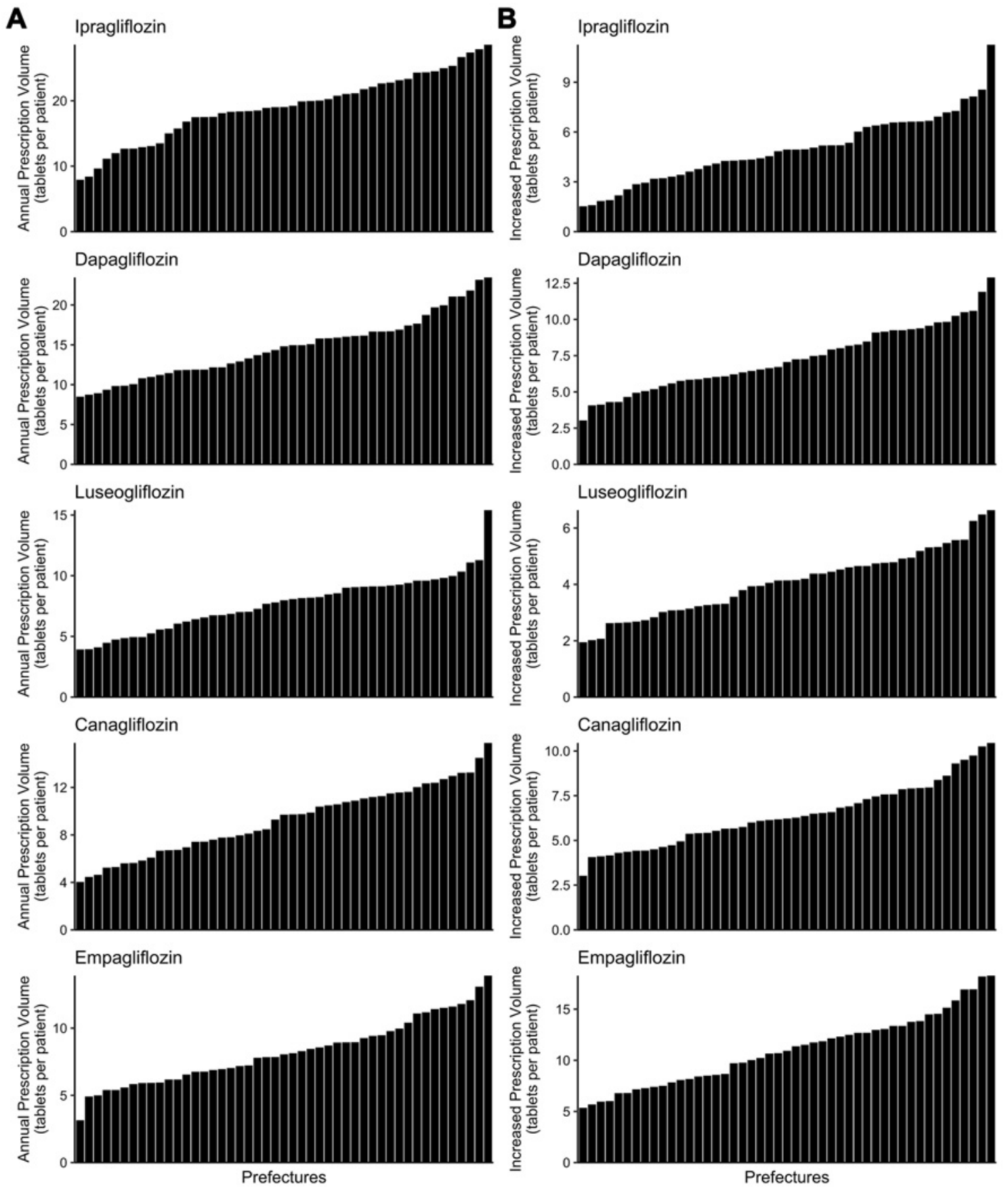

Figure 2. Regional variations in the prescription patterns of SGLT2 inhibitors in Japan. A: The annual prescription volume of SGLT2 inhibitors per patient with T2DM. B: The increased prescription volume of SGLT2 inhibitors per patient with T2DM. The black bars represent 47 prefectures in Japan. X- axis represents tablets per patient. SGLT2 inhibitors indicates sodium-glucose transporter-2 inhibitors.

ables and increased prescription volume of SGLT2 inhibitors per patient with T2DM from 2016 to 2017 are shown in Table III. SGLT2 inhibitors consistently demonstrated a positive correlation with the number of certified cardiologists per patient with T2DM. In contrast, only dapagliflozin and luseogliflozin showed a positive correlation with the number of certified diabetologists per patient with T2DM. The number of pharmacies (per 100,000 per- sons) negatively associated with the increased prescription volume except for canagliflozin. No other consistent associations were noted.

The number of certified cardiologists invariably exhibited a positive association with the annual and increased prescription volume of SGLT2 inhibitors. Multiple regression analysis was performed to illustrate the relationship between the number of certified cardiologists per 
Table II. Correlation Coefficients Between Various Factors and the Annual Prescriptions of SGLT2 Inhibitors per Patient with T2DM in Each Prefecture

\begin{tabular}{|c|c|c|c|c|c|c|c|c|c|c|}
\hline & $\begin{array}{l}\text { Ipragliflozin } \\
\text { Correlation } \\
\text { coefficient }\end{array}$ & $P$-value & $\begin{array}{c}\text { Dapagliflozin } \\
\text { Correlation } \\
\text { coefficient }\end{array}$ & $P$-value & $\begin{array}{l}\text { Luseogli- } \\
\text { flozin } \\
\text { Correlation } \\
\text { coefficient }\end{array}$ & $P$-value & $\begin{array}{l}\text { Canaglifloz- } \\
\text { in } \\
\text { Correlation } \\
\text { coefficient }\end{array}$ & $P$-value & $\begin{array}{l}\text { Empagli- } \\
\text { flozin } \\
\text { Correlation } \\
\text { coefficient }\end{array}$ & $P$-value \\
\hline Male (\%) & $\begin{array}{c}-0.068 \\
(-0.35 \\
0.22)\end{array}$ & 0.65 & $\begin{array}{c}-0.057 \\
(-0.34,0.23)\end{array}$ & 0.70 & $\begin{array}{c}-0.14 \\
(-0.13 \\
0.43)\end{array}$ & 0.36 & $\begin{array}{c}0.083 \\
(-0.21 \\
0.36)\end{array}$ & 0.58 & $\begin{array}{c}0.16 \\
(-0.13 \\
0.43)\end{array}$ & 0.28 \\
\hline Older age $(\%)$ & $\begin{array}{c}-0.0029 \\
(-0.29 \\
0.28)\end{array}$ & 0.98 & $\begin{array}{l}0.35(0.071 \\
0.58) *\end{array}$ & $0.016^{*}$ & $\begin{array}{l}0.35(0.068 \\
0.58) *\end{array}$ & $0.016^{*}$ & $\begin{array}{c}-0.11 \\
(-0.38 \\
0.19)\end{array}$ & 0.47 & $\begin{array}{c}-0.038 \\
(-0.32 \\
0.25)\end{array}$ & 0.80 \\
\hline $\begin{array}{l}\text { Population density } \\
\text { (/inhabitable area) }\end{array}$ & $\begin{array}{l}0.19(-0.10 \\
0.45)\end{array}$ & 0.20 & $\begin{array}{l}0.23(-0.10 \\
0.45)\end{array}$ & 0.12 & $\begin{array}{l}0.19(-0.10 \\
0.45)\end{array}$ & 0.20 & $\begin{array}{c}0.26 \\
(-0.028 \\
0.51)\end{array}$ & 0.076 & $\begin{array}{c}0.20 \\
(-0.096 \\
0.46)\end{array}$ & 0.19 \\
\hline $\begin{array}{l}\text { Prefectural income } \\
\text { per person (yen) }\end{array}$ & $\begin{array}{l}0.32(0.039 \\
0.56) *\end{array}$ & $0.027^{*}$ & $\begin{array}{c}0.16(-0.14 \\
0.42)\end{array}$ & 0.29 & $\begin{array}{c}0.21 \\
(-0.080 \\
0.47)\end{array}$ & 0.15 & $\begin{array}{c}0.33(0.056 \\
0.57) *\end{array}$ & $0.020 *$ & $\begin{array}{l}0.33(0.043 \\
0.56) *\end{array}$ & $0.025 *$ \\
\hline $\begin{array}{l}\text { Number of Hospitals } \\
\text { and medical clinics } \\
\text { (/100,000 persons) }\end{array}$ & $\begin{array}{c}-0.24 \\
(-0.49 \\
0.049)\end{array}$ & 0.10 & $\begin{array}{c}-0.072 \\
(-0.35,0.22)\end{array}$ & 0.63 & $\begin{array}{c}-0.042 \\
(-0.33 \\
0.25)\end{array}$ & 0.78 & $\begin{array}{c}-0.35 \\
(-0.58 \\
-0.074) *\end{array}$ & $0.015^{*}$ & $\begin{array}{l}-0.20 \\
(-0.46, \\
0.095)\end{array}$ & 0.18 \\
\hline $\begin{array}{l}\text { Hospitals and medical } \\
\text { clinics }\left(/ 100 \mathrm{~km}^{2} \text { of }\right. \\
\text { inhabitable area })\end{array}$ & $\begin{array}{l}0.17(-0.12 \\
0.44)\end{array}$ & 0.25 & $\begin{array}{c}0.22(-0.069 \\
0.48)\end{array}$ & 0.13 & $\begin{array}{c}0.20 \\
(-0.094, \\
0.46)\end{array}$ & 0.18 & $\begin{array}{c}0.23 \\
(-0.056 \\
0.49)\end{array}$ & 0.11 & $\begin{array}{c}0.182 \\
(-0.11 \\
0.45)\end{array}$ & 0.22 \\
\hline $\begin{array}{l}\text { Physicians working at } \\
\text { medical establishments } \\
\text { (/100,000 persons) }\end{array}$ & $\begin{array}{c}-0.17 \\
(-0.43 \\
0.13)\end{array}$ & 0.26 & $\begin{array}{c}0.025(-0.26 \\
0.31)\end{array}$ & 0.87 & $\begin{array}{c}-0.041 \\
(-0.32 \\
0.25)\end{array}$ & 0.78 & $\begin{array}{c}-0.23 \\
(-0.48 \\
0.063)\end{array}$ & 0.12 & $\begin{array}{c}-0.11 \\
(-0.39 \\
0.18)\end{array}$ & 0.45 \\
\hline $\begin{array}{l}\text { Pharmacies } \\
\text { (/100,000 persons) }\end{array}$ & $\begin{array}{c}-0.48 \\
(-0.67 \\
-0.22) *\end{array}$ & $<0.001 *$ & $\begin{array}{c}-0.38(-0.60 \\
-0.11) *\end{array}$ & $0.008^{*}$ & $\begin{array}{c}-0.35 \\
(-0.58 \\
-0.073) *\end{array}$ & $0.015^{*}$ & $\begin{array}{c}-0.30 \\
(-0.54 \\
-0.019) *\end{array}$ & $0.037^{*}$ & $\begin{array}{l}-0.27 \\
(-0.52 \\
0.014)\end{array}$ & 0.062 \\
\hline $\begin{array}{l}\text { Pharmacies }\left(/ 100 \mathrm{~km}^{2}\right. \\
\text { inhabitable area) }\end{array}$ & $\begin{array}{l}0.16(-0.13 \\
0.43)\end{array}$ & 0.27 & $\begin{array}{c}0.20(-0.091 \\
0.46)\end{array}$ & 0.17 & $\begin{array}{l}0.17(-0.12 \\
0.44)\end{array}$ & 0.24 & $\begin{array}{c}0.24 \\
(-0.055 \\
0.49)\end{array}$ & 0.11 & $\begin{array}{l}0.18(-0.11 \\
0.44)\end{array}$ & 0.22 \\
\hline $\begin{array}{l}\text { Number of certified } \\
\text { diabetologists (/patient } \\
\text { with T2DM) }\end{array}$ & $\begin{array}{l}0.41(0.13 \\
0.62) *\end{array}$ & $0.005^{*}$ & $\begin{array}{l}0.38(0.10 \\
0.60) *\end{array}$ & $0.009 *$ & $\begin{array}{c}0.28 \\
(-0.0094 \\
0.52)\end{array}$ & 0.058 & $\begin{array}{c}0.21 \\
(-0.081 \\
0.47)\end{array}$ & 0.16 & $\begin{array}{c}0.25 \\
(-0.043 \\
0.50)\end{array}$ & 0.095 \\
\hline $\begin{array}{l}\text { Number of certified } \\
\text { cardiologist (/patient } \\
\text { with T2DM) }\end{array}$ & $\begin{array}{l}0.50(0.25 \\
0.69) *\end{array}$ & $<0.001 *$ & $\begin{array}{l}0.58(0.35 \\
0.74) *\end{array}$ & $<0.001 *$ & $\begin{array}{l}0.57(0.34 \\
0.74) *\end{array}$ & $<0.001 *$ & $\begin{array}{l}0.44(0.18 \\
0.65) *\end{array}$ & $0.002 *$ & $\begin{array}{l}0.47(0.22 \\
0.67) *\end{array}$ & $<0.001 *$ \\
\hline
\end{tabular}

Male (\%) indicates the proportion of males in population with T2DM; Older age (\%), the proportion of those aged $>65$ years in population with T2DM. T2DM indicates type 2 diabetes mellitus; and SGLT2 inhibitors, sodium-glucose transporter-2 inhibitors. *Statistically significant factors are shown.

patient with T2DM and the prescription pattern of SGLT2 inhibitors.

In multiple regression models, the number of certified cardiologists per patient with T2DM was positively associated with the annual prescription volume of SGLT2 inhibitors, ipragliflozin $(P<0.05)$, dapagliflozin $(P<$ $0.05)$, luseogliflozin $(P=0.001)$, canagliflozin $(P<$ $0.001)$, and empagliflozin $(P<0.001)$, even after adjusting for sex, age, prefectural income, number of pharmacies, and number of certificated diabetologists per patient with T2DM as shown in Model 3 (Table IV). The number of certified cardiologists per patient with T2DM was consistently positively associated with the increased prescription volume of SGLT2 inhibitors, ipragliflozin $(P<0.05)$, dapagliflozin $(P<0.05)$, canagliflozin $(P<0.05)$, and empagliflozin $(P<0.001)$, even after adjusting for sex, age, number of pharmacies, and number of certificated diabetologists per patient with T2DM as shown in Model 3. The only exception was for luseogliflozin in Model 3 (Table V).

\section{Discussion}

Several findings were obtained from the analysis of the national claim database. First, the annual prescription amount of each SGLT2 inhibitor substantially increased from 2016 to 2017. Second, there were regional variations in the prescription patterns of SGLT2 inhibitors, despite the exiguous heterogeneity of ethnicity and the universal health insurance system in Japan. Third, certified cardiologists' areal distribution is positively associated with the annual and increased prescription volume of SGLT2 inhibitors.

Large-scale trials investigated the clinical effects of SGLT2 inhibitors on cardiovascular mortality and morbidity in patients with T2DM. ${ }^{1-3,15)}$ Thereafter, SGLT2 inhibitors have displayed a steady increase in their prescription in the $\mathrm{US}^{16)}$ and the UK, ${ }^{12)}$ which is consistent with the findings of our study. We illustrated that regional variations in the prescription pattern of SGLT2 inhibitors are associated with certified cardiologists' distribution patterns among prefectures. Multiple regression analyses revealed 
Table III. Correlation Coefficients Between Various Factors and the Increase in Prescriptions for SGLT2 Inhibitors per Patient with T2DM in Each Prefecture

\begin{tabular}{|c|c|c|c|c|c|c|c|c|c|c|}
\hline & $\begin{array}{l}\text { Ipragliflozin } \\
\text { Correlation } \\
\text { coefficient }\end{array}$ & $P$-value & $\begin{array}{l}\text { Dapagliflozin } \\
\text { Correlation } \\
\text { coefficient }\end{array}$ & $P$-value & $\begin{array}{l}\text { Luseogliflozin } \\
\text { Correlation } \\
\text { coefficient }\end{array}$ & $P$-value & $\begin{array}{l}\text { Canagliflozin } \\
\text { Correlation } \\
\text { coefficient }\end{array}$ & P-value & $\begin{array}{l}\text { Empagliflozin } \\
\text { Correlation } \\
\text { coefficient }\end{array}$ & $P$-value \\
\hline Male (\%) & $\begin{array}{c}-0.020 \\
(-0.31,0.27)\end{array}$ & 0.90 & $\begin{array}{c}-0.003 \\
(-0.29,0.28)\end{array}$ & 0.98 & $\begin{array}{c}-0.008 \\
(-0.29,0.28)\end{array}$ & 0.96 & $\begin{array}{c}0.011(-0.28 \\
0.30)\end{array}$ & 0.94 & $\begin{array}{c}0.13(-0.16 \\
0.40)\end{array}$ & 0.38 \\
\hline Older age (\%) & $\begin{array}{c}0.058(-0.23 \\
0.34)\end{array}$ & 0.70 & $\begin{array}{c}0.22(-0.069 \\
0.48)\end{array}$ & 0.13 & $\begin{array}{l}0.17(-0.12 \\
0.44)\end{array}$ & 0.24 & $\begin{array}{c}0.031(-0.26 \\
0.32)\end{array}$ & 0.84 & $\begin{array}{c}0.030(-0.26 \\
0.31)\end{array}$ & 0.84 \\
\hline $\begin{array}{l}\text { Population density } \\
\text { (/inhabitable area) }\end{array}$ & $\begin{array}{c}-0.008 \\
(-0.29,0.28)\end{array}$ & 0.96 & $\begin{array}{c}0.25(-0.043 \\
0.50)\end{array}$ & 0.093 & $\begin{array}{c}0.21(-0.082 \\
0.47)\end{array}$ & 0.16 & $\begin{array}{c}-0.042 \\
(-0.32,0.25)\end{array}$ & 0.78 & $\begin{array}{c}0.16(-0.14 \\
0.43)\end{array}$ & 0.29 \\
\hline $\begin{array}{l}\text { Prefectural income } \\
\text { per person (yen) }\end{array}$ & $\begin{array}{c}0.066(-0.23 \\
0.35)\end{array}$ & 0.66 & $\begin{array}{c}0.13(-0.16 \\
0.40)\end{array}$ & 0.38 & $\begin{array}{c}0.25(-0.036 \\
0.50)\end{array}$ & 0.085 & $\begin{array}{c}0.017(-0.27 \\
0.30)\end{array}$ & 0.91 & $\begin{array}{c}0.27(-0.015 \\
0.52)\end{array}$ & 0.063 \\
\hline $\begin{array}{l}\text { Number of Hospitals } \\
\text { and medical clinics } \\
\text { (/100,000 persons) }\end{array}$ & $\begin{array}{c}-0.14(-0.41 \\
0.15)\end{array}$ & 0.33 & $\begin{array}{c}-0.11(-0.39 \\
0.18)\end{array}$ & 0.46 & $\begin{array}{c}-0.022 \\
(-0.31,0.27)\end{array}$ & 0.88 & $\begin{array}{c}-0.23(-0.48, \\
0.064)\end{array}$ & 0.12 & $\begin{array}{c}-0.26(-0.51 \\
0.032)\end{array}$ & 0.081 \\
\hline $\begin{array}{l}\text { Hospitals and } \\
\text { medical clinics } \\
\text { (/100 } \mathrm{km}^{2} \text { of } \\
\text { inhabitable area) }\end{array}$ & $\begin{array}{c}-0.014 \\
(-0.30,0.27)\end{array}$ & 0.93 & $\begin{array}{c}0.23(-0.062 \\
0.48)\end{array}$ & 0.12 & $\begin{array}{c}0.21(-0.082 \\
0.47)\end{array}$ & 0.16 & $\begin{array}{c}-0.053 \\
(-0.34,0.24)\end{array}$ & 0.72 & $\begin{array}{l}0.14(-0.15 \\
\quad 0.41)\end{array}$ & 0.35 \\
\hline $\begin{array}{l}\text { Physicians } \\
\text { working at medical } \\
\text { establishments } \\
\text { (/100,000 persons) }\end{array}$ & $\begin{array}{c}-0.15(-0.42 \\
0.15)\end{array}$ & 0.32 & $\begin{array}{c}-0.025 \\
(-0.31,0.26)\end{array}$ & 0.87 & $\begin{array}{l}0.10(-0.19 \\
\quad 0.38)\end{array}$ & 0.50 & $\begin{array}{c}-0.14(-0.41, \\
0.15)\end{array}$ & 0.35 & $\begin{array}{c}-0.17(-0.44 \\
0.2)\end{array}$ & 0.24 \\
\hline $\begin{array}{l}\text { Pharmacies } \\
\text { (/100,000 } \\
\text { persons) }\end{array}$ & $\begin{array}{c}-0.30(-0.54 \\
-0.015)^{*}\end{array}$ & $0.039^{*}$ & $\begin{array}{c}-0.30(-0.54 \\
-0.015) *\end{array}$ & $0.039 *$ & $\begin{array}{c}-0.32(-0.55 \\
-0.033) *\end{array}$ & $0.029 *$ & $\begin{array}{c}-0.17(-0.44, \\
0.12)\end{array}$ & 0.24 & $\begin{array}{c}-0.35(-0.58 \\
-0.065) *\end{array}$ & $0.017 *$ \\
\hline $\begin{array}{l}\text { Pharmacies } \\
\left(/ 100 \mathrm{~km}^{2}\right. \\
\text { inhabitable area) }\end{array}$ & $\begin{array}{c}-0.025 \\
(-0.31,0.26)\end{array}$ & 0.87 & $\begin{array}{c}0.22(-0.069 \\
0.48)\end{array}$ & 0.13 & $\begin{array}{l}0.19(-0.10 \\
\quad 0.45)\end{array}$ & 0.20 & $\begin{array}{c}-0.058 \\
(-0.34,0.23)\end{array}$ & 0.70 & $\begin{array}{l}0.14(-0.16 \\
\quad 0.41)\end{array}$ & 0.36 \\
\hline $\begin{array}{l}\text { Number of certified } \\
\text { diabetologists } \\
\text { (/patient with } \\
\text { T2DM) }\end{array}$ & $\begin{array}{c}0.27(-0.023 \\
0.51)\end{array}$ & 0.070 & $\begin{array}{l}0.40(0.12 \\
0.62) *\end{array}$ & $0.005^{*}$ & $\begin{array}{l}0.48(0.22 \\
0.67) *\end{array}$ & $<0.001 *$ & $\begin{array}{c}0.24(-0.054 \\
0.49)\end{array}$ & 0.11 & $\begin{array}{c}0.27(-0.015 \\
0.52)\end{array}$ & 0.062 \\
\hline $\begin{array}{l}\text { Number of certified } \\
\text { cardiologist (/patient } \\
\text { with T2DM) }\end{array}$ & $\begin{array}{l}0.41(0.13 \\
0.62) *\end{array}$ & $0.005^{*}$ & $\begin{array}{l}0.53(0.29 \\
0.71) *\end{array}$ & $<0.001^{*}$ & $\begin{array}{l}0.57(0.34 \\
0.74) *\end{array}$ & $<0.001 *$ & $\begin{array}{l}0.40(0.12 \\
0.61) *\end{array}$ & $0.006^{*}$ & $\begin{array}{l}0.50(0.24 \\
0.69) *\end{array}$ & $0.003 *$ \\
\hline
\end{tabular}

Male (\%) indicates the proportion of males in population with T2DM; Older age (\%), the proportion of those aged $>65$ years in population with T2DM. T2DM indicates type 2 diabetes mellitus; and SGLT2 inhibitors, sodium-glucose transporter-2 inhibitors. * Statistically significant factors are shown.

that the annual prescription amount of SGLT2 inhibitors was larger and increased more rapidly in areas that had a larger number of certified cardiologists per patient with $\mathrm{T}$ 2DM. Although the relationship was not produced in Model 3 for the increased prescription of luseogliflozin, we believe that this negative observation resulted from multicollinearity of this model. In the univariate analysis, the increased prescription amount of luseogliflozin has the highest correlation coefficient with the number of certified diabetologists per patient with T2DM, leading to the negative association. We suspected that this negativity derived from the current analysis using region-based parameters, one of the limitations of this study, as described later.

High expectations for cardiovascular protection of SGLT2 inhibitors among cardiologists might explain this unique tendency in our study. The first large-scale clinical trial that showed cardiovascular protection of SGLT2 inhibitors was EMPA-REG OUTCOME study, published in December 2015. ${ }^{1)}$ The next large-scale clinical trial was CANVAS published in August 2017, which demonstrated that canagliflozin provides cardiovascular protective effects. ${ }^{2)}$ Because the claim data covers the period between April 2016 and March 2018, this result may reflect the impact of the EMPA-REG OUTCOME study on routine clinical practice, but not CANVAS or other studies. Nevertheless, the tendency was observed in the analysis for the other SGLT2 inhibitors than empagliflozin. This exceptional result could be explained by clinicians expecting a class effect for the other SGLT2 inhibitors, despite the lack of clinical evidence. ${ }^{17)}$

Additionally, in the present study, the number of certified diabetologists was less associated with the annual and increased prescription volume of SGLT2 inhibitors than certified cardiologists. A possible explanation for this might be a circumspect attitude among diabetologists for prescribing SGLT2 inhibitors based on the recommendations for their appropriate use, released by the Japan Diabetes Society. ${ }^{18)}$ The warnings for their use include increased risks of ketoacidosis, dehydration, skin symptoms, and urogenital infections. ${ }^{18)}$ The milder relation of SGLT2 inhibitor prescription to the diabetologist density could also be explained by the fact that the specialists recognize other therapeutic options and optimize patient care using other diabetic drugs to avoid polypharmacy, which reduces medical adherence. ${ }^{19)}$ In addition, cardiologists who daily treat patients with ischemic heart disease or conges- 


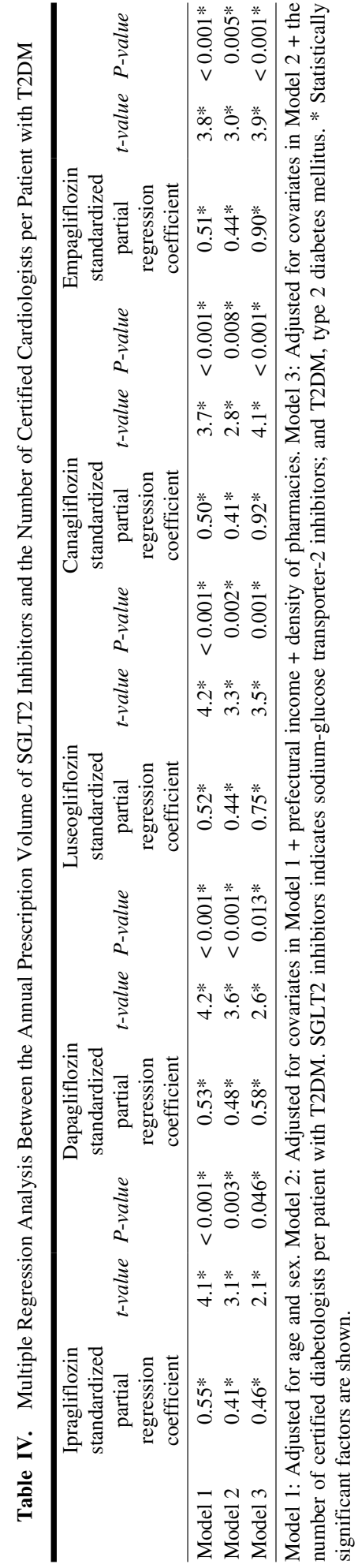

tive heart failure strongly related to T2DM may have higher expectations for SGLT2 inhibitors than diabetologists.

In contrast to the results of our analysis, according to a report from an integrated tertiary care system, cardiolo-

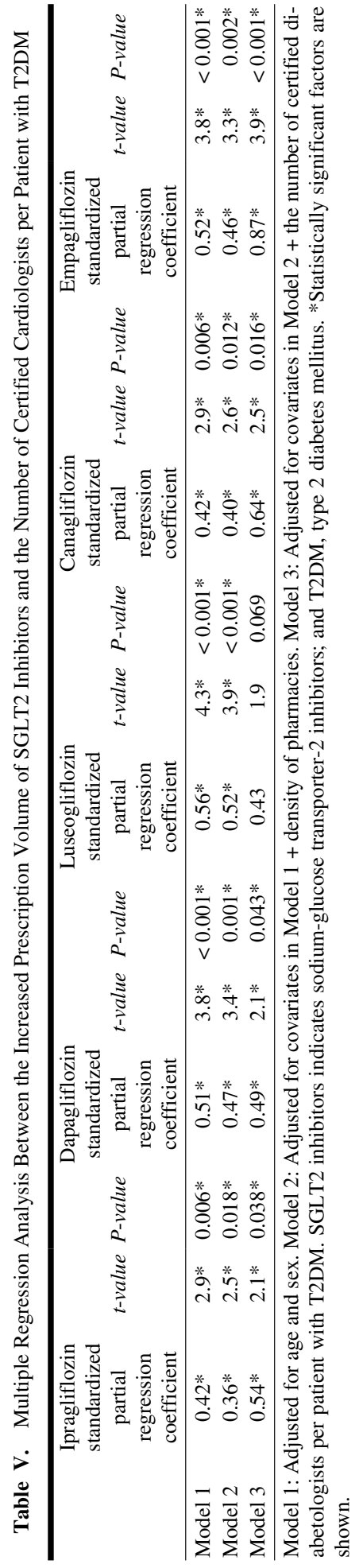

gists prescribed only $5 \%$ of all SGLT2 inhibitors, whereas endocrinologists prescribed approximately 50\%. ${ }^{14)}$ As the authors noted in their report, this tendency may not be generalizable across all settings. In the report, the transition of the number of prescriptions sensitively reflected new evidence, including the release of the results of the 
EMPA-REG OUTCOME trial and initial US Food and Drug Administration safety communications for canagliflozin. Therefore, this report represented well-educated and well-informed physicians. Our study was nationwide and included nearly all prescription data in Japan, through the use of the NDB, based on which several epidemiological studies were published..$^{20-25)}$ Of note, the NDB has increasingly attracted attention, and the number of studies using the NDB has grown rapidly. ${ }^{26)}$

As those previous database studies suggested, it is necessary to ponder appropriateness of regional factors as explanatory variables. They generally have easier access to newer and more expensive medications in urban areas compared to rural areas. Then, we evaluated the association of population density with the prescription pattern in the univariate analyses. Considering the negative results, we selected prefectural income and number of pharmacies, instead of population density, as explanatory variables according to their $P$-values.

As evidence of the beneficial effects of SGLT2 inhibitors accumulates, cardiologists' preferred prescription of SGLT2 inhibitors may hold far into the future. First, SGLT2 inhibitors can be one of the main options for treating chronic heart failure, although their broad application as an official recommendation depends on further clinical evidence accumulation. DAPA-HF and EMPEROR-Reduced demonstrated that dapagliflozin and empagliflozin lowered the risk of worsening heart failure or cardiovascular mortality in patients with heart failure and a reduced ejection fraction regardless of diabetes mellitus, respectively., ${ }^{5,6}$ These and subsequent trials may change cardiologists' view on selecting therapeutic agents for treating chronic heart failure, possibly strengthening the tendency of the prescription pattern that our study exhibited. Moreover, recent studies have reported possible renoprotection of SGLT2 inhibitors. ${ }^{2,27-30)}$ Canagliflozin and Renal Events in Diabetes and Nephropathy Clinical Evaluation finally uncovered the renal protective effects of SGLT2 inhibitors as a primary endpoint in diabetic patients. ${ }^{15)}$ Surprisingly, the Dapagliflozin and Prevention of Adverse Outcomes in Chronic Kidney Disease (DAPACKD) trial demonstrated renal protection of dapagliflozin, independent of the presence of diabetes. ${ }^{30)}$ Previous reports from Japan showed regional variations in prescribing patterns for angiotensin-converting enzyme inhibitors ${ }^{31}$ and chronic kidney disease (CKD)-related drugs, such as phosphate binders and erythropoiesis-stimulating agents. ${ }^{24}$ In particular, the prescription of CKD-related drugs was positively associated with the number of certified nephrologists. ${ }^{24)}$ Future studies are warranted to analyze the annual alteration in SGLT2 inhibitor prescription by nephrologists and cardiologists.

Several limitations of our study should be acknowledged. First, because the study is observational to analyze region-based parameters solely, it is unknown whether the cardiologists considered in the study prescribed SGLT2 inhibitors. In this regard, further studies are required to elucidate the contribution of certified cardiologists to the prescription pattern of SGLT2 inhibitors and diabetic patient care by prescribing them. Second, the characteristics of a claim database disabled us to have access to clinical conditions where each SGLT2 inhibitor was prescribed. It has been reported that a large number of patients with $\mathrm{T} 2$ DM in the USA who were potentially eligible for SGLT2 inhibitors were not prescribed these drugs. ${ }^{32)}$ Further studies to evaluate the appropriateness of SGLT2 inhibitors are warranted. Third, patients who are social welfareentitled and prescribed SGLT2 inhibitors as a part of comprehensive medical care were originally excluded due to the nature of the NDB. The total number of individuals on social welfare was as low as 16.9 per 1,000 persons in Japan in 2016 (https://www.mhlw.go.jp/toukei/list/10-20. html (in Japanese) [accessed January 5, 2020]). The validity of excluding these patients from our analysis remains to be evaluated. Fourth, the current study mainly addressed variables at a prefecture-level. With smaller analytical frameworks such as municipalities, a finer prescription pattern could be clarified.

In conclusion, our nationwide database study highlights regional variations in the prescription patterns of SGLT2 inhibitors in Japan. Furthermore, we demonstrate that the number of certified cardiologists is positively associated with the annual and increased prescription volume of SGLT2 inhibitors. Despite several limitations, this study advocates certified cardiologists' contributions to spread a new medication to overcome an evidencepractice gap.

\section{Disclosure}

Conflicts of interest: $\mathrm{HN}$ has received a lecture fee from Astellas. MN has received honoraria, advisory fees, or research funding from Astellas, AstraZeneca, Bayer, Boehringer Ingelheim, Daiichi Sankyo, GSK, JT, Kyowa Kirin, Takeda, Torii, Mitsubishi Tanabe, and Ono.

\section{References}

1. Zinman B, Wanner C, Lachin JM, et al. Empagliflozin, cardiovascular outcomes, and mortality in Type 2 diabetes. $\mathrm{N}$ Engl $\mathrm{J}$ Med 2015; 373: 2117-28.

2. Neal B, Perkovic V, Mahaffey KW, et al. Canagliflozin and cardiovascular and renal events in Type 2 diabetes. N Engl J Med 2017; 377: 644-57.

3. Wiviott SD, Raz I, Bonaca MP, et al. Dapagliflozin and cardiovascular outcomes in Type 2 diabetes. N Engl J Med 2019; 380: 347-57.

4. Arnott C, Li Q, Kang A, et al. Sodium-glucose cotransporter 2 inhibition for the prevention of cardiovascular events in patients with type 2 diabetes mellitus: a systematic review and metaanalysis. J Am Heart Assoc 2020; 9: e014908.

5. McMurray JJV, Solomon SD, Inzucchi SE, et al. Dapagliflozin in patients with heart failure and reduced ejection fraction. $\mathrm{N}$ Engl J Med 2019; 381: 1995-2008.

6. Packer M, Anker SD, Butler J, et al. Cardiovascular and renal outcomes with empagliflozin in heart failure. N Engl J Med 2020; 383: 1413-24.

7. Cannon CP, Pratley R, Dagogo-Jack S, et al. Cardiovascular outcomes with ertugliflozin in Type 2 diabetes. N Engl J Med 2020; 383: 1425-35.

8. American Diabetes Association. 8. Pharmacologic approaches to glycemic treatment. Diabetes Care 2017; 40: S64-74.

9. Inzucchi SE, Bergenstal RM, Buse JB, et al. Management of hyperglycemia in type 2 diabetes: a patient-centered approach: 
position statement of the American Diabetes Association (ADA) and the European Association for the Study of Diabetes (EASD). Diabetes Care 2012; 35: 1364-79.

10. Haneda M, Noda M, Origasa H, et al. Japanese clinical practice guideline for diabetes 2016. J Diabetes Investig 2018; 9: 65797.

11. Mainz J. Defining and classifying clinical indicators for quality improvement. Int J Qual Health Care 2003; 15: 523-30.

12. Whyte MB, Hinton W, McGovern A, et al. Disparities in glycaemic control, monitoring, and treatment of type 2 diabetes in England: a retrospective cohort analysis. PLOS Med 2019; 16: e1002942.

13. McCoy RG, Dykhoff HJ, Sangaralingham L, et al. Adoption of new glucose-lowering medications in the US.-the case of SGLT 2 inhibitors: nationwide cohort study. Diabetes Technol Ther 2019; 21: 702-12.

14. Vaduganathan M, Sathiyakumar V, Singh A, et al. Prescriber patterns of SGLT2i after expansions of US. Food and Drug Administration labeling. J Am Coll Cardiol 2018; 72: 3370-2.

15. Perkovic V, Jardine MJ, Neal B, et al. Canagliflozin and renal outcomes in Type 2 diabetes and nephropathy. $\mathrm{N}$ Engl J Med 2019; 380: 2295-306.

16. Raval AD, Vyas A. National trends in diabetes medication use in the United States: 2008-2015. J Pharm Pract 2020; 33: 433-42.

17. Giugliano D, Esposito K. Class effect for SGLT-2 inhibitors: a tale of 9 drugs. Cardiovasc Diabetol 2019; 18: 94.

18. Committee on the Proper Use of SI. Recommendations on the proper use of SGLT2 inhibitors. Diabetol Int 2020; 11: 1-5.

19. Cramer JA. A systematic review of adherence with medications for diabetes. Diabetes Care 2004; 27: 1218-24.

20. Koyama T, Zamami Y, Ohshima A, Teratani Y, Shinomiya K, Kitamura Y. Patterns of CT use in Japan, 2014: a nationwide cross-sectional study. Eur J Radiol 2017; 97: 96-100.

21. Kamata Y, Minota S. Wide difference in biologics usage and expenditure for the treatment of patients with rheumatoid arthritis in each prefecture in Japan analyzed using "National Database of Health Insurance Claims and Specific Health Checkups of Japan”. Rheumatol Int 2018; 38: 663-8.

22. Kumamaru KK, Machitori A, Koba R, Ijichi S, Nakajima Y,
Aoki S. Global and Japanese regional variations in radiologist potential workload for computed tomography and magnetic resonance imaging examinations. Jpn J Radiol 2018; 36: 27381 .

23. Itoh H, Saito T, Nojiri S, Hiratsuka Y, Yokoyama K. National burden of the pharmaceutical cost of wet compresses and its cost predictors: nationwide cross-sectional study in Japan. Health Econ Rev 2019; 9: 20.

24. Inoue R, Nishi H, Tanaka T, Nangaku M. Regional variance in patterns of prescriptions for chronic kidney disease in Japan. Clin Exp Nephrol 2019; 23: 859-64.

25. Inoue R, Nishi H, Inoue D, Honda K, Nangaku M. Regional variance of the early use of tolvaptan for autosomal dominant polycystic kidney disease. Kidney360 2020; 1: 740-5.

26. Hirose N, Ishimaru M, Morita K, Yasunaga H. A review of studies using the Japanese National Database of Health Insurance Claims and Specific Health Checkups. Ann Clin Epidemiol 2020; 2: 13-26.

27. Wanner C, Inzucchi SE, Lachin JM, et al. Empagliflozin and progression of kidney disease in Type 2 diabetes. N Engl J Med 2016; 375: 323-34.

28. Perkovic V, de Zeeuw D, Mahaffey KW, et al. Canagliflozin and renal outcomes in type 2 diabetes: results from the CANVAS Program randomised clinical trials. Lancet Diabetes Endocrinol 2018; 6: 691-704.

29. Mosenzon O, Wiviott SD, Cahn A, et al. Effects of dapagliflozin on development and progression of kidney disease in patients with type 2 diabetes: an analysis from the DECLARE-TIMI 58 randomised trial. Lancet Diabetes Endocrinol 2019; 7: 606-17.

30. Heerspink HJL, Stefánsson BV, Correa-Rotter R, et al. Dapagliflozin in patients with chronic kidney disease. N Engl J Med 2020; 383: 1436-46.

31. Usami T, Nakao N, Fukuda M, et al. Maps of end-stage renal disease and amounts of angiotensin-converting enzyme inhibitors prescribed in Japan. Kidney Int 2003; 64: 1445-9.

32. Arnold SV, Inzucchi SE, Tang F, et al. Real-world use and modeled impact of glucose-lowering therapies evaluated in recent cardiovascular outcomes trials: an $\mathrm{NCDR}^{\circledR}$ research to practice project. Eur J Prev Cardiol 2017; 24: 1637-45. 